\title{
Burden of fall injuries in Pakistan - analysis of the National Injury Survey of Pakistan
}

A.M. Bachani, ${ }^{1}$ A. Ghaffar ${ }^{2}$ and A.A. Hyder ${ }^{1}$

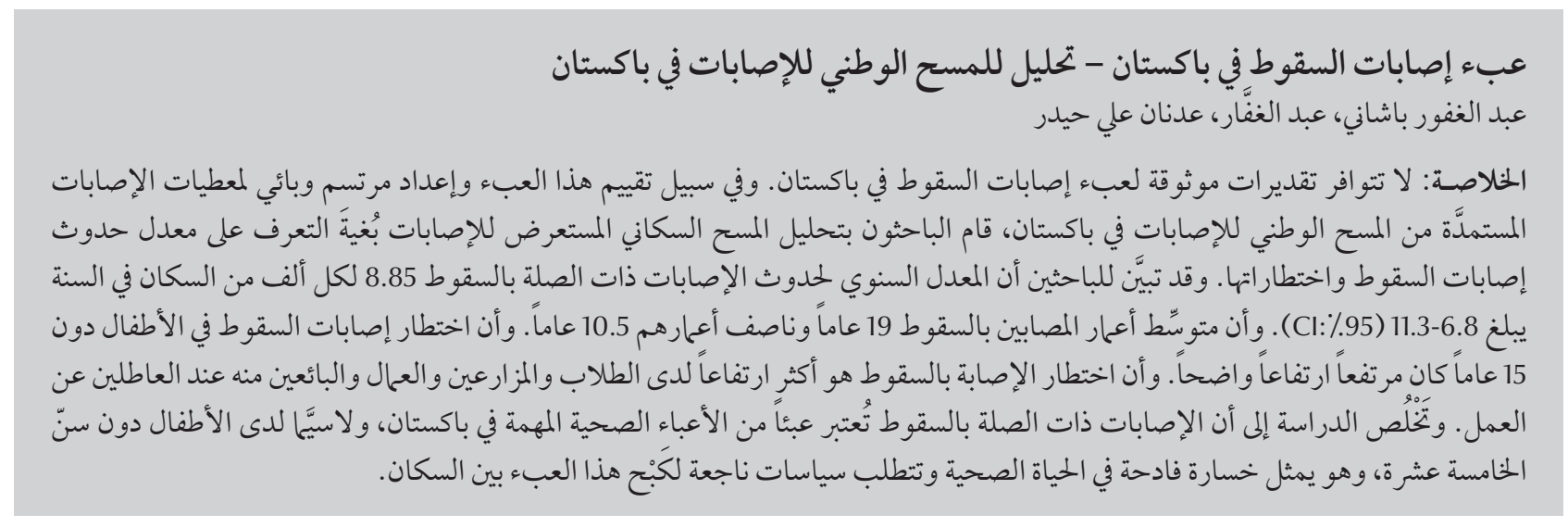

ABSTRACT There are no reliable estimates of the burden of fall-related injuries in Pakistan. To assess this burden and develop an epidemiologic profile for these injuries data from the National Injury Survey of Pakistan, a crosssectional population-based survey on injuries, were analysed to determine incidence and relative risks for fall injury. The annual incidence of fall-related injuries was 8.85 per 1000 population per year (95\% Cl: 6.8-11.3). The mean and median age of individuals injured by falls was 19 years and 10.5 years respectively. Children under the age of 15 years were at a substantially higher risk of fall injuries. Being a student and farmer/labourer/vendor were associated with a higher risk for falls compared with unemployed. Fall-related injuries are a health burden in Pakistan, especially in children under 15 years of age. This represents a significant loss of healthy life and requires policies to curb this burden in the population.

\section{Charge des traumatismes par chute au Pakistan - analyse de l'enquête nationale sur les traumatismes}

RÉSUMÉ II n'existe pas d'estimations fiables concernant la charge des traumatismes liés aux chutes au Pakistan. Pour évaluer cette charge et brosser un profil épidémiologique à partir des données issues de l'enquête nationale sur les traumatismes au Pakistan, une enquête transversale en population sur les traumatismes a été analysée afin de déterminer l'incidence et les risques relatifs de traumatismes par chute. L'incidence annuelle des traumatismes liés aux chutes était de 8,85 pour 1000 habitants par an (IC à $95 \%: 6,8-11,3$ ). L'âge moyen et l'âge médian des personnes souffrant d'un traumatisme par chute étaient 19 ans et 10,5 ans, respectivement. Les enfants de moins de 15 ans avaient un risque nettement supérieur de traumatismes par chute. Le fait d'être étudiant, fermier/cultivateur/vendeur était associé à un risque accru de chute par rapport aux personnes sans emploi. Les traumatismes liés à une chute représentent une charge pour la santé au Pakistan, en particulier chez les enfants de moins de 15 ans. Ils induisent une perte importante d'années de vie en bonne santé et appellent des politiques visant à réduire cette charge dans la population.

'International Injury Research Unit, Department of International Health, Johns Hopkins University Bloomberg School of Public Health, Baltimore, United States of America.

${ }^{2}$ World Health Organization, Geneva, Switzerland (Correspondence to A. Ghaffar: ghaffara@who.int).

Received: 30/09/09; accepted: 11/11/09 


\section{Introduction}

Unintentional injuries are increasingly being recognized as a major public health problem globally [1-4]. The World Health Organization estimates that injuries currently account for $15 \%$ of global disability-adjusted life year (DALY) losses. This proportion is expected to rise considerably within the next decade and it is estimated that by the year 2020, injuries will contribute to $20 \%$ of all DALY losses $[3,5]$. The vast majority of these losses occur in lowand middle-income countries, where they have a tremendous impact on society - both in health and economic terms $[2-4,6]$.

Worldwide, fall injuries claim the lives of almost 400000 individuals annually, ranking second after road traffic injuries in terms of mortality due to unintentional injuries [7]. With the high morbidity associated with injuries, it is expected that the number of individuals living with varying levels of disability due to falls is several fold higher $[7,8]$. Most of these individuals are believed to live in low- and middle-income countries $[2,4]$. Despite these figures, there is a dearth of fall prevention programmes in low- and middle-income countries; one important reason is the lack of reliable and accurate populationlevel epidemiological data on fall injuries $[6,7,9]$. Most of the data on fall injuries in low- and middle-income countries are obtained from hospital or police reports which are often incomplete and not representative of the burden of fall injuries in the population $[6,7,9,10]$. A recent systematic review of published and unpublished literature on falls by Hyder and colleagues [7] revealed that population-level data on injuries from low-income countries is significantly lacking and highlights the urgent need for such information.

In Pakistan, unintentional injuries have consistently ranked high among theleading contributors of burden of disease [6,9-12]. However, in the absence of reliable estimates of the burden of fall injuries, it has been difficult to get the attention of policy-makers $[6,7,9,12]$. Cross-sectional population surveys can provide estimates of such injury burden on Pakistani society $[9,13]$.

In light of this, the National Injury Survey of Pakistan (NISP) was designed and carried out in Pakistan in 1997, to comprehensively define the epidemiology of injuries in Pakistan $[9,12]$. This was the first such survey targeting injuries in Pakistan, and attempted to identify groups that are most at risk of different types of injuries [9]. The survey sought to identify the incidence of injuries, their frequency and distribution by age, gender, place of residence, educational status, and profession $[9,12]$. Data from this survey have previously been analysed with respect to the overall incidence of injuries and road traffic injuries in particular [9]. In that analysis, road traffic injuries were found to be the leading cause of injuries in Pakistan, and mostly affected individuals between the ages of 16 and 45 years, males, labourers and vendors [9]

No attempt has been made to develop an epidemiologic profile for fallrelated injuries in Pakistan thus far. This paper is intended to further analyse the data from the NISP for risk factors associated with falls in the Pakistani population. Since different kinds of injuries and categories of individuals would require different preventive interventions or case management, developing an epidemiological profile of fall-related injuries would aid in the identification of groups most affected by such injuries as well as provide more concrete direction for further research, in-depth surveillance and better targeting

\section{Methods}

NISP was a 3-month recall survey of a representative sample of the population in Pakistan; the structure of the survey, its design, sampling scheme and study population have been previously described in detail $[9,12]$. In brief, the NISP was a nationally representative survey, administered at the household level, with the respondent being heads of households or the senior most member of the household present at the time of the interview $[9,12]$. Its objective was to identify the incidence and describe the epidemiology of injuries in the population $[9,12]$. An injury, for the purposes of this survey, was defined as injury to any part of the body in the 3 months prior to the survey that either resulted in death, seeking medical care, or loss of at least half a day of normal daily activities $[9,12]$.

For the present analysis, the yearly incidence of all injuries as well as fallrelated injuries was calculated per 1000 individuals in the Pakistani population and annual estimates obtained. Further analysis of fall-related injuries excluded individuals with other injuries. Data stratification and analyses were done using STATA statistical software [14].

To analyse falls in the Pakistani population, the data was first categorized into age, gender, residence, education and occupation categories. Age had 4 categories ( $<15$ years, $15-44$ years, $45-59$ years and $\geq 60$ years), and place of residence was stratified into 3 categories (semi-urban, rural and urban). For educational status, individuals under the age of 15 years were excluded to examine the effect that education had on falls in individuals who were past high-school age. This was done to avoid the bias that may have arisen due to the expected lower levels of education in younger individuals. Educational status was thus stratified into 3 categories: no education, $1-5$ years of education and $\geq 6$ years of education. Occupation was categorized into 7 categories: unemployed/at home, student, service/ paid formal labour market employee, farmer, labourer, vendor (shop owner/ street seller), and businessman. Children under the age of 10 years and who stayed at home were excluded from the 
"unemployed/at home" category for the analysis of the effect of occupation on fall-related injuries. This age group was, however, included in the analysis of the effect of all the other categories of occupation. This would allow evaluation of the true effect of occupation on fall-related injuries without bias arising due to the many children who stay at home, while at the same time allowing a study of the effect of child labour, if any, in the population.

Three-way cross-tabulations for age, gender, education and occupation were first done to gain a better understanding of the data and distribution of falls. Univariate analysis was then done for each risk factor to obtain unadjusted estimates of relative risks (RRs) of fallrelated injury and the corresponding 95\% confidence intervals ( $\mathrm{CIs}$ ) using the epitab commands in STATA [14]. The reference groups for each of the categories were: $<15$ years for age; female for gender; semi-urban for place of residence; $\geq 6$ years of schooling for education; and at home/unemployed for occupation. These reference categories were selected to maintain comparability between this analysis and the previously reported analysis for road traffic injuries using data from the NISP [9].

Regression analyses to obtain adjusted estimates were done using generalized linear models [15]. The modified Poisson model was used [15,16]; this model was preferred over the logistic modelbecause firstly, itgave RRsinstead of odds ratios, and secondly, the modified Poisson model provided a better fit for the data than the logistic model, as assessed with the Pearson chi-squared test, and deviance. However, before a decision was made, both models, as well as a log-binomial model and a negative binomial model, were compared and yielded very similar results.

Adjusted RRs were obtained using models that included a combination of age, gender, place of residence and occupation. Two such models were used - one with educational level and the other without. Education was excluded from the second model because it would have otherwise limited the analysis to individuals over the age of 15 years only, and thus would have reduced the number of observations included in the analysis. The first model was therefore used to obtain an adjusted estimate for education, whereas the second model was used to get estimates for all the other factors.

\section{Results}

In total, 28921 individuals were surveyed by the NISP. The survey population was almost evenly split between the 2 genders (male: $14900,52 \%$; female: $13791,48 \%)$ and the 3 areas of residence (semi-urban: $28 \%$, rural: $38 \%$ and urban: $34 \%)$ (Table 1). Individuals $<45$ years accounted for almost $90 \%$ of the surveyed population, whereas almost half of the respondents had no formal schooling, with a majority of them being females (64\%) (Table 1).

There were a total of 294 injuries reported; of these, $22 \%$ were fall-related injuries (64 fall-related injuries). This corresponds to an annual incidence of 8.85 per 1000 population per year (CI: 6.8-11.3) for fall-related injuries. The mean age of individuals injured by falls was 19 years, and the median age was 10.5 years. More than half of all fall-related injuries reported in the survey (59\%) occurred in individuals $<15$ years of age; males accounted for $58 \%$ of fall injuries (13.8 injuries per 1000 peryear); and individuals who were unemployed and students accounted for $21 \%$ and $45 \%$ of fall injuries respectively (Table 1).

Cross-tabulation of injuries by gender, age and educational level (Table 2a) revealed that overall, children 15 years and under accounted for the majority of falls (59\%) in this population. A similar breakdown for categories of occupation (Table $2 b$ ) showed that $45 \%$ of the falls were concentrated in school-students, with twice as many males having fall-related injuries as females. Among women, those staying at home accounted for $50 \%$ of all the falls; the only other fall for a woman was a female labourer over the age of 60 (Table 2b). In males, farmers, labourers and vendors accounted for $30 \%$ of falls (Table 2b).

Overall, males had a higher risk of fall-related injuries than females (males: 10.5/1000/year; Females: 7.3/1000/ year). This difference was however not statistically significant (RR: 1.4, CI: 0.87-2.39) (Table 3). Looking at age, the overallincidence of fall-related injury was highest in children $<15$ years (11.9 injuries per 1000 per year). The rates decreased as age increased - individuals aged 15-59 years were between $40 \%$ and $60 \%$ less likely to be injured by falls than were individuals $<15$ years of age (Table 3). Females between the ages of 15 and 44 years had an $81 \%$ lower risk of falls compared to their younger counterparts (Table 3).

Regarding residence, although the overall incidence of falls was lowest in a semi-urban setting, it was not much different from the incidence of falls in rural or urban settings (Table3). Males living in both rural and urban areas had a 1.62 and 2.03 times higher risk of being injured due to a fall than their counterparts residing in a semi-urban setting, although this difference was not statistically significant (Table 3).

Analysis by education revealed a $71 \%$ lower risk of fall-related injuries in individuals who had $1-5$ years of schooling compared to individuals who had $\geq 6$ years of formal education (Table $3)$; individuals who had no schooling, when compared to those who had $\geq 6$ years of education, also had a lower risk of falls, which again was not statistically significant (Table 3).

Occupation seemed to play a significant role in the risk of fall-related injuries in Pakistan. Businessmen had the lowest incidence of fall-related 


\begin{tabular}{|c|c|c|c|c|c|c|}
\hline \multirow[t]{3}{*}{ Variable } & \multicolumn{3}{|c|}{ Demographics } & \multicolumn{3}{|c|}{ Distribution of falls } \\
\hline & Males & Females & Total & Males & Females & Total \\
\hline & No. (\%) & No. (\%) & No. (\%) & No. & No. & No. \\
\hline \multicolumn{7}{|l|}{ Age (years) } \\
\hline$<15$ & $6732(52)$ & $6094(48)$ & $12826(45)$ & 22 & 16 & 38 \\
\hline $15-44$ & $6089(51)$ & $5948(49)$ & $12037(42)$ & 17 & 3 & 20 \\
\hline $45-59$ & $1284(53)$ & $1127(47)$ & $2411(8)$ & 0 & 3 & 3 \\
\hline$\geq 60$ & $795(56)$ & $622(44)$ & $1417(5)$ & 0 & 3 & 3 \\
\hline \multicolumn{7}{|l|}{ Residence } \\
\hline Semi-urban & $4227(53)$ & $3796(47)$ & $8023(28)$ & 7 & 9 & 16 \\
\hline Rural & $5606(51)$ & $5392(49)$ & $10998(38)$ & 15 & 10 & 25 \\
\hline Urban & $5067(52)$ & $4603(48)$ & $9670(34)$ & 17 & 6 & 23 \\
\hline \multicolumn{7}{|l|}{ Educational level $^{a}$} \\
\hline$\geq 6$ years of schooling & $3984(70)$ & $1716(30)$ & $5700(37)$ & 10 & 2 & 12 \\
\hline $1-5$ years of schooling & $1000(61)$ & 639 (39) & 1639 (11) & 0 & 1 & 1 \\
\hline No schooling & $2862(36)$ & $5019(64)$ & $7881(52)$ & 7 & 6 & 13 \\
\hline \multicolumn{7}{|l|}{ Occupation $^{b}$} \\
\hline Unemployed/at home & $1115(14)$ & $6903(86)$ & $8026(35)$ & 2 & 8 & 10 \\
\hline Student & $4134(54)$ & $3516(46)$ & $7650(27)$ & 15 & 7 & 22 \\
\hline Service/paid employee & $1785(87)$ & $270(13)$ & $2055(7)$ & 4 & 0 & 4 \\
\hline Farmer & $937(97)$ & $25(3)$ & $962(3)$ & 3 & 0 & 3 \\
\hline Labourer & $1634(97)$ & $56(3)$ & $1690(6)$ & 4 & 1 & 5 \\
\hline Vendor & $851(93)$ & $61(7)$ & $912(3)$ & 3 & 0 & 3 \\
\hline Businessman & 1350 (98) & $31(2)$ & $1381(5)$ & 2 & 0 & 2 \\
\hline Totalc & $14900(52)$ & $13791(48)$ & $28691(100)$ & $39(61 \%)$ & $25(39 \%)$ & $64(100 \%)$ \\
\hline
\end{tabular}

${ }^{a}$ Individuals $<15$ years were excluded.

"Individuals $<10$ years were excluded from the "unemployed/at home" category.

cAll falls total number excludes individuals with other injuries.

injuries and represented a risk of such injuries similar to individuals who were unemployed or stayed at home (Table 3). Students, on the other hand, were more than twice as likely to be injured by a fall as individuals staying at home or who were unemployed $(\mathrm{RR}=2.32$, CI: 1.1-4.9, $P<0.05)$. A significantly increased risk of such injuries was also observed in farmers, labourers and vendors combined $(\mathrm{RR}=2.5, \mathrm{CI}: 1.1-5.8)$ (Table 3).

\section{Discussion}

The NISP was undertaken to collect injury information from a representative sample of the Pakistani population $[9,12]$. Our analysis of data from this national survey showed that Pakistan has a burden of fall-related injuries with an incidence of 8.85 per 1000 per year. This is in concordance with findings from previous studies in the country and the region as a whole $[7,10,11]$. From the present analysis, it appears that the categories most at risk for fallrelated injuries are individuals 15 years of age or under; students; and farmers, labourers and vendors. Males residing in urban areas of Pakistan also have an increased risk of falls.

These findings, when compared to the burden of road trafficinjuries derived from the same data [9], indicate that labourers and vendors are more likely to suffer falls and road traffic injuries; both these occupations are considered occupations of the lower socioeconomic strata. This finding is of significance for policy and prevention strategies since the data also reveal that the injured are mostly males between the ages of 15 and 44 years. This represents a group of people who, in a society such as $\mathrm{Pa}$ kistan, are mostly the bread-winners of such lower income households [12,17]. The high rate of fall-related injuries in these groups could be explained by the kind of work they do and the high-risk environment they are subjected to due to their occupation $[6,12]$. Improvements in conditions at work-places, implementation of safe working practices and policies requiring employers to ensure a safe working environment for their employees may thus be potential interventions [6]. 


\begin{tabular}{|c|c|c|c|}
\hline Age and education & $\begin{array}{c}\text { Males } \\
\text { No. (\%) }\end{array}$ & $\begin{array}{l}\text { Females } \\
\text { No. (\%) }\end{array}$ & $\begin{array}{c}\text { Total } \\
\text { No. }(\%)\end{array}$ \\
\hline Less than 15 years & $22(56 \%)$ & $16(64 \%)$ & $38(59 \%)$ \\
\hline 15 years and over & $17(44 \%)$ & $9(36 \%)$ & $26(41 \%)$ \\
\hline No schooling & 7 & 6 & 13 \\
\hline Some schooling & 10 & 3 & 13 \\
\hline Total & 39 & 25 & 64 \\
\hline
\end{tabular}

Table 2b Distribution of fall injuries: cross-tabulation by gender and occupation

\begin{tabular}{lccc} 
Occupation & $\begin{array}{c}\text { Males } \\
\text { No. (\%) }\end{array}$ & $\begin{array}{c}\text { Females } \\
\text { No. }(\%)\end{array}$ & $\begin{array}{c}\text { Total } \\
\text { No. }(\%)\end{array}$ \\
Unemployed/at home & $2(6 \%)$ & $8(50 \%)$ & $10(21 \%)$ \\
Student & $15(46 \%)$ & $7(44 \%)$ & $22(45 \%)$ \\
Service/paid employee & $4(12 \%)$ & $0(0 \%)$ & $4(8 \%)$ \\
Farmer, labourer or vendor & $10(30 \%)$ & $1(6 \%)$ & $11(22 \%)$ \\
Businessman & $2(6 \%)$ & $0(0 \%)$ & $2(4 \%)$ \\
Total & 33 & 16 & 49 \\
\hline
\end{tabular}

Children under the age of 10 years and who stayed at home were excluded.

Place ofresidence also had an impact on the risk of falls in Pakistani men. This finding is supported by studies from other developing countries in Africa, where individuals living in urban areas are at an increased risk of falls, especially from high buildings $[18,19]$. This is an issue of concern for Pakistan, where the level of urbanization has significantly increased since 1997, when the survey was carried out [11], implying that emphasis needs to be made on better planning of development projects and urban centres in general.

An important finding of the study is that children under the age of 15 years are at a significantly higher risk of falls than older individuals. This finding is consistent with other recent reports from the region and elsewhere in the developing world $[7,11,20]$. In fact, a comparison of these findings to a recent systematic review of global literature for falls in children revealed that the burden of falls in children $0-15$ years in Pakistan is at the higher end of the spectrum of fall injuries in this age group worldwide; and certainly higher than the estimate for the Asian region [7].
This is of concern as falls in children could lead to life-long disabilities or even death, and therefore represent a large loss of healthy life $[7,9,10]$. This health burden can be significant, as seen from recent findings in Turkey and $\mathrm{Ne}-$ pal, where falls are responsible for $40 \%$ and $60 \%$ of childhood trauma or neurotrauma cases presenting at hospitals or emergency rooms respectively $[21,22]$. Reports from Pakistan and developing countries further indicate that falls were among the leading causes of head, spinal cord and orofacial injuries in children [23-25].

Several factors may be contributing to the increased risk of falls in children $<15$ years; previous studies in different regions of Pakistan have found that the high number of young children in families, unsupervised children while parents are at work and kite flying were associated with fall-related injuries in children and young adults $[12,26]$. Falls in children have also been previously reported to commonly occur inside the home $[11,20]$. These factors and others (such as child labour) need to be examined in detail before appropriate policy and preventive measures can be instituted. Safer playing facilities for children and increased emphasis on adult supervision may be potential interventions that could address this situation [27].

Falls in those $\geq 45$ years seems to be a problem in Pakistani women, especially with no education, and in the home environment. As these are women who are nearing or already in menopause and may be suffering from osteoporosis, falls could have potentially significant and far-reaching health impacts. Falls have also been identified as one of the leading causes of death from injuries in this age group $[28,29]$. This is a problem that has been highlighted in both the developed and developing world, and one that needs to be considered in healthcare planning and delivery - especially primary and home-based care, in a country such as Pakistan [28].

Limitations of the NISP have been previously described in detail $[9,12]$. However, it is important to note here that due to the nature of the questions that were asked in the survey, and its design, namely the 3-month recall period, it was difficult for the survey to: identify the specific environment and conditions surrounding the various injuries; measure "permanent disability"; and measure fatality due to injuries $[9,12]$ The design also limits the survey to capturing only those injuries that were serious enough to seek medical attention $[9,12]$. As a result, the findings from this survey are thought to be a conservative estimate of the true burden of falls in the Pakistani population, especially given that in addition to minor injuries that were not reported, a large proportion of the population does not have access to medical care $[3,9,12]$.

A significant limitation in this analysis is the small sample of falls in the survey population, which led to very few numbers in some categories. Since the NISP was designed to evaluate the overall impact of all injuries and identify general risk factors $[9,12]$, the 


\begin{tabular}{|c|c|c|c|c|}
\hline 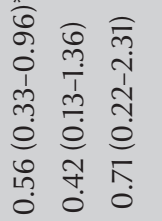 & 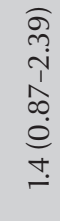 & 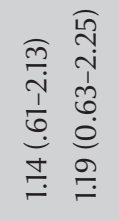 & 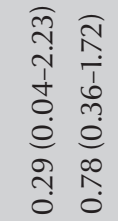 & 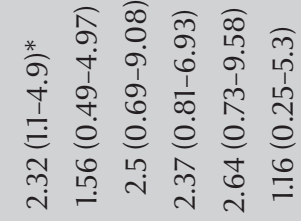 \\
\hline
\end{tabular}

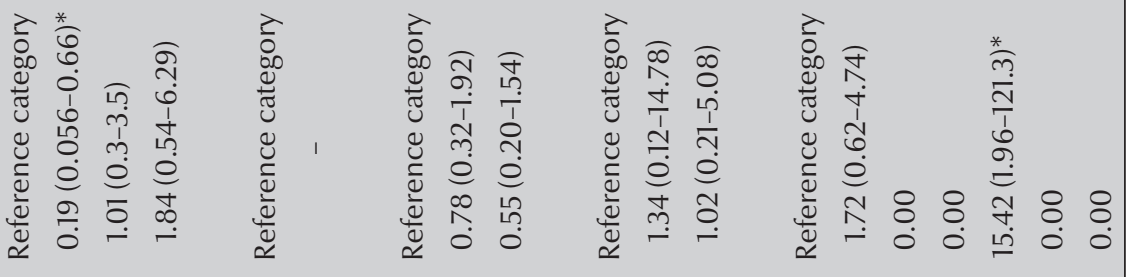

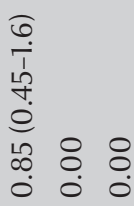

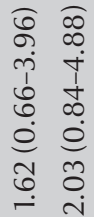

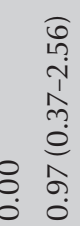

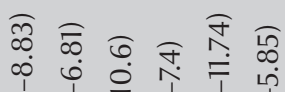

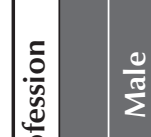

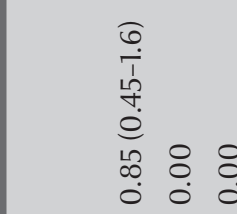

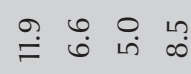

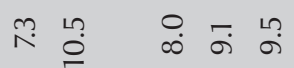

$\stackrel{+}{+} \stackrel{+}{i} \quad \stackrel{0}{0}$

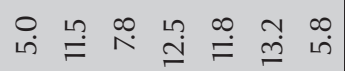

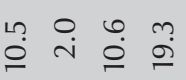

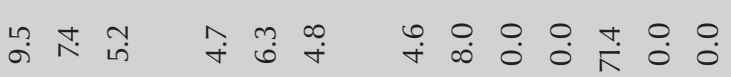

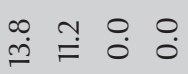

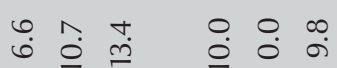

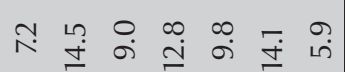

$\stackrel{2}{\circ}$

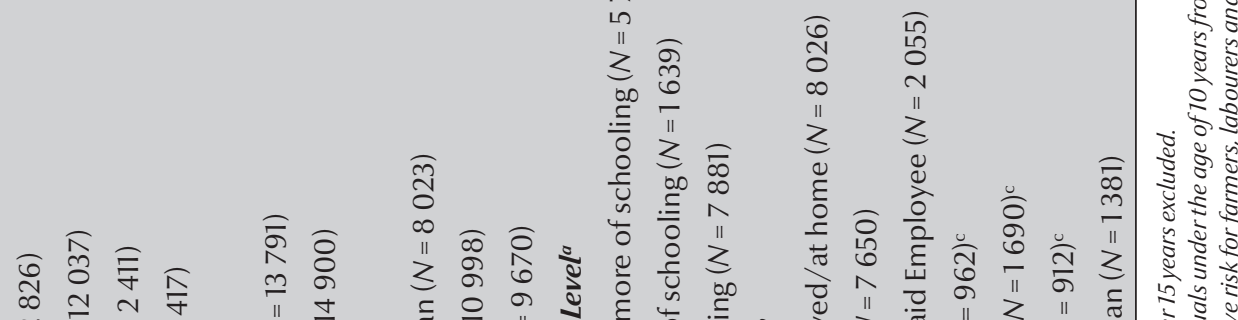

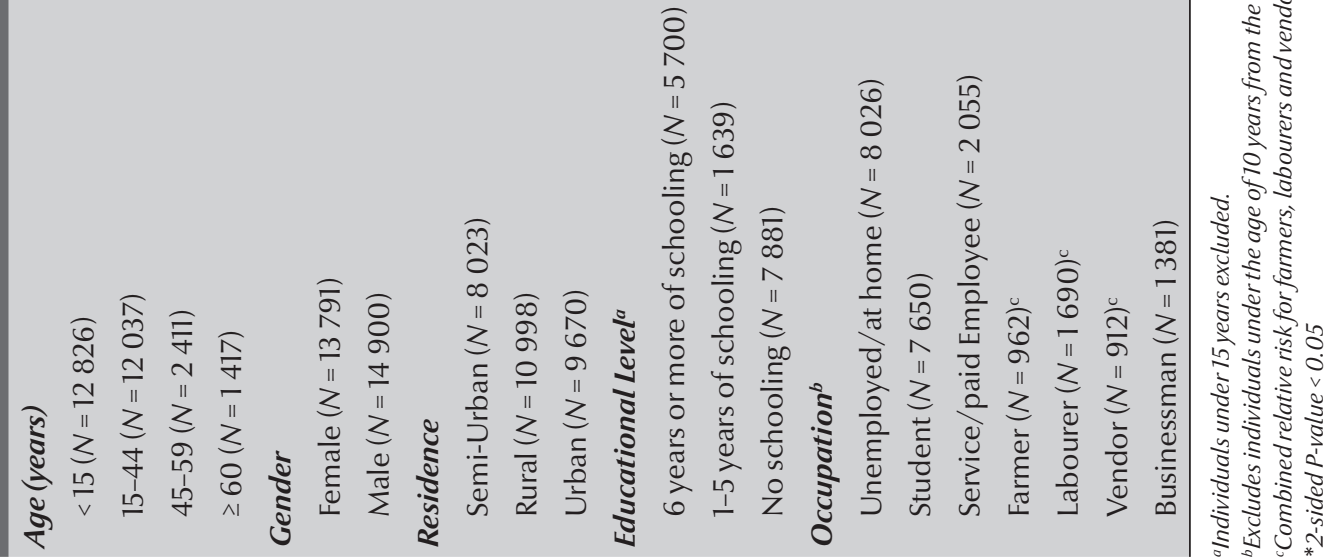


sample size may not have been large enough to assess the same for each individual type of injury. This serves as a learning point for future national population-based surveys intended to evaluate specific injuries or other "rare" events/conditions; it may be necessary to "over-sample" in order to better assess the specific risk factors associated with each subset of injuries in the population.

This analysis of data from the NISP reveals that the burden of fall-related injuries in Pakistan is comparable to current national and regional estimates from other low- and middle-income countries $[1,2,4,7,9,11,19]$. Therefore, based on these findings and the 2008 population in Pakistan [30], it is estimated that more than 1.4 million individuals of all ages will be seriously injured due to a fall, with 850000 or more of these being children under the age of 15 years, not counting fatalities. These findings reflect a problem in Pakistan - one that has not been addressed yet [11]. Future studies are thus necessary to analyse the specific risk factors of fall injuries in children as well as those in farmers, labourers and vendors. Policy and prevention efforts could then be appropriately implemented to reduce the burden of falls on these populations. Such data in Pakistan, as well as other regions of the world, would be necessary and invaluable to policy-makers, public health practitioners, and programme administrators in developing policies and programmes.

\section{References}

1. Krug EG, Sharma GK, Lozano R. The global burden of injuries American Journal of Public Health, 2000, 90:523-526.

2. The injury chart book: A graphical overview of the global burden of injuries. Geneva, World Health Organization, 2002.

3. World Health Report 2000 -Measuring Health Systems Performance. Geneva, World Health Organization, 2000.

4. Injury: A Leading Cause of the Global Burden of Disease. Geneva, World Health Organization, 2002

5. Murray CJ, Lopez AD. Alternative projections of mortality and disability by cause 1990-2020: Global Burden of Disease Study. Lancet, 1997, 349:1498-1504.

6. Ghaffar A et al. Injuries in Pakistan: directions for future health policy. Health Policy and Planning, 1999, 14:11-17.

7. Hyder AA et al. Falls among children in the developing world: A gap in child health burden estimations? Acta Paediatrica (Oslo, Norway), 2007, 96:1394-1398.

8. Child and adolescent injury prevention: A global call to action. Geneva, Switzerland: World Health Organization; 2005.

9. Ghaffar A, Hyder AA, Masud TI. The burden of road traffic injuries in developing countries: the 1st national injury survey of Pakistan. Public Health, 2004, 118:211-217.

10. Razzak JA et al. Injuries among children in Karachi, Pakistanwhat, where and how. Public Health, 2004, 118:114-120.

11. Fatmi $Z$ et al. Incidence, patterns and severity of reported unintentional injuries in Pakistan for persons five years and older: results of the National Health Survey of Pakistan 1990-94. BMC Public Health, 2007, 7:152

12. Ghaffar A et al. National injury survey of Pakistan (NISP 19971999). Islamabad, Pakistan, National Injury Research Center (NIRC), Health Services Academy, Ministry of Health, Government of Pakistan; 2001.

13. Fisher G, Pappas G, Limb M. Prospects, problems, and prerequisites for national health examination surveys in developing countries. Social Science \& Medicine, 1996, 42:1639-1650.

14. Statacorp. Stata statistical software. College Station, Texas, United States of America, 2005:9.

15. Lindquist $\mathrm{K}$. How to estimate relative risk using glm for common outcomes in cohort studies [UCLA Stata FAQ Web site]. (http://www.ats.ucla.edu/STAT/stata/faq/relative_risk.htm, accessed 29 March 2011),

16. Zou G. A modified poisson regression approach to prospective studies with binary data. American Journal of Epidemiology, 2004, 159:702-706.
17. Hadden WC, Pappas G, Khan AQ. Social stratification, development and health in Pakistan: an empirical exploration of relationships in population-based national health examination survey data. Social Science \& Medicine, 2003, 57:1863-1874.

18. Ka AS et al. Epidemiology and prognosis of childhood injuries in Dakar, Senegal. Medecine Tropicale, 2003, 63:533-538.

19. Moshiro $\mathrm{C}$ et al. Injury morbidity in an urban and a rural area in Tanzania: an epidemiological survey. BMC Public Health, 2005, 5:11.

20. Bangdiwala SI, Anzola-Pérez E. The incidence of injuries in young people: II. Log-linear multivariable models for risk factors in a collaborative study in Brazil, Chile, Cuba and Venezuela. International Journal of Epidemiology, 1990, 19:125-132.

21. Mukhida K, Sharma MR, Shilpakar SK. Pediatric neurotrauma in Kathmandu, Nepal: implications for injury management and control. Child's Nervous System, 2006, 22:352-362.

22. Gürses D et al. Cost factors in pediatric trauma. Canadian Journal of Surgery, 2003, 46:441-445.

23. Lawoyin TO, Lawoyin DO, Lawoyin JO. Factors associated with oro-facial injuries among children in Al-Baha, Saudi Arabia. African Journal of Medicine and Medical Sciences, 2002, 31:37-40.

24. Liko $\mathrm{O}$ et al. Head injuries in Papua New Guinea. Papua and New Guinea Medical Journal, 1996, 39:100-104.

25. Okonkwo CA. Spinal cord injuries in Enugu, Nigeria-preventable accidents. Paraplegia, 1988, 26:12-18.

26. Berger LR, Mohan D. Injury control: A global view. Delhi, India, Oxford University Press, 1996.

27. Kendrick D et al. "Risk Watch": cluster randomised controlled trial evaluating an injury prevention program. Injury Prevention, 2007, 13:93-98.

28. Oliver D. Older people who fall: why they matter and what you can do. British Journal of Community Nursing, 2007, 12:500-507.

29. Sattin RW et al. The incidence of fall injury events among the elderly in a defined population. American Journal of Epidemiology, 1990, 131:1028-1037.

30. CIA. The World Factbook - Pakistan. The World Factbook 2007 Web site. (https://www.cia.gov/library/publications/ the-world-factbook/print/pk.html. Updated 2007. Accessed December 11, 2007). 